http://dx.doi.org/10.32929/2446-8355.2019v28n2p204-214

\title{
DESEMPENHO PRODUTIVO DO TOMATEIRO SOB CULTIVO PROTEGIDO UTILIZANDO CALDAS AGROECOLÓGICAS
}

\author{
Ivo Dahlke ${ }^{1}$, Divanilde Guerra ${ }^{2 *}$, Eduardo Lorensi de Souza², Mastrângello Enivar \\ Lanzanova $^{2}$, Robson Evaldo Gehlen Bohrer ${ }^{2}$, Maiara Figueiredo Ramires ${ }^{3}$
}

\footnotetext{
${ }^{1}$ Engenheiro Agrônomo, Especialista em Segurança Alimentar e Agroecologia, Universidade Estadual do Rio Grande do Sul - UERGS, Unidade em Três Passos, RS.

2 Professor Adjunto, Agronomia e Gestão Ambiental, Universidade Estadual do Rio Grande do Sul - UERGS, Unidade em Três Passos, RS. *E-mail do autor correspondente: divanilde-guerra@uergs.edu.br

${ }^{3}$ Doutora, Ciência do Solo, Universidade Federal de Santa Maria - UFSM, Santa Maria, RS.
}

Recebido: 04/11/2018; Aceito: 28/06/2019

\begin{abstract}
RESUMO: O tomate é um alimento rico em ácidos orgânicos e vitaminas, os quais são indispensáveis para a nutrição dos seres humanos, porém o cultivo convencional utiliza em seu manejo, agrotóxicos que podem deixar resíduos nos frutos e comprometer a saúde dos consumidores. O objetivo desse estudo foi avaliar o desempenho produtivo do tomateiro sob cultivo protegido quando manejados com caldas agroecológicas. $\mathrm{O}$ arranjo experimental constou de uma variedade de tomate e três tratamentos fitossanitários, cada qual com cinco repetições, em um delineamento inteiramente casualizado. Os tratamentos testados foram T1 (convencional); T2 (em transição para orgânico) e T3 (testemunha). No T2 as caldas foram utilizadas de forma preventiva e alternadas, uma por semana, e os resultados de produtividade foram comparados com o tratamento convencional e a testemunha. Como resultado se observou que o T1, a base de agrotóxicos foi mais produtivo com média de $3,6 \mathrm{~kg}_{\text {planta }}{ }^{-1}$; o T2 também resultou em boa produção e qualidade de frutos, com média de 3,2 $\mathrm{kg} \mathrm{planta}^{-1}$, enquanto que a testemunha (T3) apresentou a menor produção, com 2,5 kg planta ${ }^{-1}$. Portanto, o uso de caldas é viável na produção de tomates sob cultivo protegido.
\end{abstract}

Palavras-chave: Solanum lycopersicon. Agroecologia. Compostos Fitoterápicos.

\section{PRODUCTIVE PERFORMANCE OF TOMATOES UNDER PROTECTED CULTIVATION USING AGROECOLOGICAL CALDAS}

\begin{abstract}
Tomato is a food rich in organic acids and vitamins, which are indispensable for human nutrition, but conventional farming uses agrochemicals that can leave residues on the fruits and compromise the health of consumers. The objective of this study was to evaluate the productive performance of tomato under protected cultivation when managed with agroecological grouts. The experimental arrangement consisted of a tomato variety and three phytosanitary treatments, each with five replications, in a completely randomized design. The treatments tested were T1 (conventional); T2 (in transition to organic) and T3 (control). At T2 the syrup were used preventively and alternately, one per week, and the productivity results were compared with the conventional treatment and the control. As a result, it was observed that $\mathrm{T} 1$, the pesticide base was more productive with an average of 3.6
\end{abstract}


kg plant-1; T2 also resulted in good yield and fruit quality, with a mean of $3.2 \mathrm{~kg}$ plant-1, while the control (T3) had the lowest production, with $2.5 \mathrm{~kg}$ plant-1. Therefore, the use of syrups is feasible in the production of tomatoes under protected cultivation.

Key words: Solanum lycopersicon. Agroecology. Herbal compounds.

\section{INTRODUÇÃO}

O tomate (Solanum lycopersicum) pertencente à família das Solanáceas está entre as hortaliças do tipo fruto mais consumidas no mundo (FAO, 2019), pois é uma importante fonte de vitaminas e sais minerais, além de ácido fólico, frutose e o antioxidante licopeno (GONDIM, 2016).

Segundo dados da Organização das Nações Unidas para a Alimentação e a Agricultura (FAO, 2019), a produção mundial de tomates em 2017 foi de aproximadamente 130 milhões de toneladas ano, das quais cerca de 88,0 milhões de toneladas foram destinadas ao consumo do fruto in natura e as outras 42,0 milhões de toneladas destinadas a indústria. A China foi o maior produtor mundial com 52,5 milhões de toneladas, representando $31 \%$ da produção do planeta, sendo seguida pela Índia com $11 \%$ e pelos Estados Unidos, que produz $8 \%$ do volume global. O Brasil encontra-se na nona posição com 2,5\% da produção mundial, onde são plantados anualmente aproximadamente 64,4 mil hectares de tomateiros (IBGE, 2019).

Nos sistemas de produção convencional de tomates, muito produtos químicos são utilizados, sendo alguns de forma inadequada. Segundo informações do Programa de Análise de Resíduos de Agrotóxicos em Alimentos da Agência Nacional de Vigilância Sanitária (ANVISA, 2019), através da análise de quase 2.500 amostras de alimentos em 2018, $32,6 \%$ das amostras de tomate apontaram agrotóxicos acima do permitido. Desta forma, fica evidente que o consumo de alimentos oriundos da agricultura convencional, a qual utiliza como técnica de manejo a aplicação de elevadas concentrações de agrotóxicos tem provocado na população a insegurança alimentar, bem como, despertado uma preocupação com a qualidade dos alimentos e a saúde dos consumidores (MELO et al., 2009; BRAGA, 2014; FERREIRA; BRAGANÇA COELHO, 2017).

Devido ao uso excessivo de produtos químicos e seus resíduos nos alimentos tem se ampliado o interesse por práticas agrícolas consideradas alternativas, como a agricultura biodinâmica, natural, sustentável, ecológica, regenerativa, biológica, agroecológica e permacultura (CAMPOS et al., 2015). Assim sendo, a agricultura orgânica vem se tornando uma alternativa para a produção de alimentos mais saudáveis, pois está impulsiona várias mudanças nas formas de se pensar e produzir produtos orgânicos de qualidade e que não agridem o meio ambiente, contribuindo assim para a conservação dos recursos naturais das propriedades agrícolas (NICOLA et al., 2016). Segundo Resende; Braga (2014) o cultivo de orgânicos tem se expandido no Brasil, pois são estáveis, produtivos, de elevada eficiência na utilização de recursos naturais e que resultam em alimentos saudáveis, livres de agrotóxicos e produzidos em total harmonia com a natureza. 
$\mathrm{Na}$ cultura do tomateiro, o emprego de caldas, tais como a bordalesa, viçosa, sulfocálcica e a adoção do uso de adubos naturais no cultivo orgânico surgiram há poucos anos e vem permitindo a obtenção de resultados satisfatórios em relação à produtividade e redução dos problemas fitossanitários (SOUZA, 2010). Ainda, de acordo com Resende; Braga (2014) os sistemas orgânicos de produção de tomates permitem maior obtenção de renda devido ao aumento do valor agregado no produto final, bem como, não necessita de grandes áreas para sua produção e ainda, a dependência por insumos externos é reduzida, visto que a maioria dos produtos podem ser obtidos nos próprios sistemas de produção.

As propriedades fitossanitárias das plantas são um modelo para a síntese de pesticidas naturais mais eficientes, menos tóxicos e com menor persistência no meio ambiente, e que ajudam a entender a complexa interação entre os seres vivos no ecossistema (SAITO; LUCHINI, 1998). Para a utilização de plantas e seus componentes, a Instrução Normativa do Ministério da Agricultura, Pecuária e Abastecimento nº 46 de 06 de outubro de 2011, traz uma série de substâncias que podem ser utilizadas como insumos na agricultura orgânica (BRASIL, 2011). E a Instrução Normativa Conjunta SDA/SPRC $\mathrm{n}^{\circ} 1$, de 6 de novembro de 2015, regulamenta os produtos fitossanitários com o uso aprovado nos sistemas orgânicos de produção (BRASIL, 2015).

Nesse sentido, a produção de alimentos oriundos da agricultura orgânica tem apresentado crescimento de $15 \%$ a $20 \%$ por ano, enquanto setores como a indústria cresceram de 4 a 5\% (MARINI et al., 2016). Segundo os autores, este resultado está associado a um crescente no número de consumidores preocupados principalmente com a questão da saúde e biodiversidade. Posto isto, devido a uma demanda crescente por produtos hortícolas de qualidade e sem residual de agrotóxicos, este trabalho teve como objetivo avaliar a eficiência do controle fitossanitário realizado por meio da aplicação de caldas agroecológicas na produção de tomates sob cultivo protegido.

\section{MATERIAL E MÉTODOS}

O estudo foi realizado em uma propriedade agrícola no município de Tiradentes do Sul,

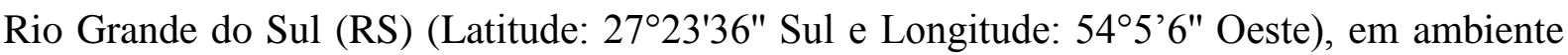
protegido (estufa), com dimensões de $5 \mathrm{~m}$ x $25 \mathrm{~m}$ em estrutura simples e em madeira, recoberta por plástico filme de polietileno agrícola, com irrigação em sistema de gotejamento. O solo do experimento é classificado como Neossolo (SANTOS, 2013), com as seguintes características: raso pedregoso, classe textural 3, com $27 \%$ de argila, P: $30,0 \mathrm{mg} \mathrm{L}^{-1}, \mathrm{~K}: 186$ mg L'-1, M.O: $2,4 \%$.

O clima na região é classificado como Cfa, na classificação de Köppen e a temperatura média anual é de $19,3^{\circ} \mathrm{C}$. O mês mais quente corresponde a janeiro, no qual a temperatura média é de $24,6^{\circ} \mathrm{C}$. O mês mais frio corresponde a junho, no qual a temperatura média é de $14,0^{\circ} \mathrm{C}$.

O arranjo experimental constou de uma variedade de tomate e três tratamentos fitossanitários, cada qual com cinco repetições, em um delineamento inteiramente 
casualizado. Os tratamentos testados são descritos a seguir: T1 (convencional); T2 (em transição para orgânico) e T3 (testemunha).

No T1 foram aplicados os tratamentos fitossanitários tradicionalmente utilizados pelo produtor, isto é, o uso de fungicidas comerciais para o tomateiro conforme as recomendações para a cultura.

Os fungicidas utilizados foram: a) fungicida com os ingredientes ativos stiofanatometilico e clorotalonil, ou seja, um fungicida da classe sistêmico e de contato do grupo químico dos benzimidazole, b) fungicida de ingrediente ativo azoxistrobinae difenoconazol, fungicida sistêmico do grupo químico azoxistrobina; estrobilurina; difenoconazoletriazol, denominado de fungicida 2. As aplicações do fungicida 1 ocorreram aos 30 e 60 dias após o plantio, através da adição de 40g do produto comercial em 20 litros de água. Posteriormente procedeu-se a aplicação do fungicida 2 , sendo este utilizado a cada 15 dias $(6 \mathrm{ml}$ do produto comercial em 20 litros de água), totalizando seis aplicações. O volume de calda utilizado em cada aplicação foi de aproximadamente 500 L por hectare.

No T2 foram utilizados três produtos de base natural: a) MTC - Bordapest calda bordalesa pronta (produto comercial); b) MTC - Curapest (produto comercial); c) Composto fitoterápico formulado artesanalmente com cavalinha, flores de camomila, alho e cebola. $\mathrm{O}$ composto fitoterápico é um formulado composto por $200 \mathrm{~g}$ de folhas de Cavalinha (Equisetum sp), $150 \mathrm{~g}$ de flores de Camomila (Matricária recutita), $200 \mathrm{~g}$ de Alho (Azadirachta indica), $200 \mathrm{~g}$ de Cebola (Allium cepa), 3 litros de álcool (98\%) e 1,5 litros de água, os quais foram armazenados por 48 horas, e tendo seu volume final de $10 \mathrm{~L}$ completado com água.

No T2, foram utilizadas pulverizações alternadas, semanais e preventivas; o procedimento de pulverização teve início com o MTC-Bordapest, na proporção de $250 \mathrm{ml}$ do produto comercial em $10 \mathrm{~L}$ de água; posteriormente procedeu-se a aplicação do MTCCurapest, na proporção de $500 \mathrm{ml}$ em $10 \mathrm{~L}$ de água; e por fim o Composto fitoterápico, na proporção de $500 \mathrm{ml}$ em $10 \mathrm{~L}$ de água. Após esta sequência (aplicação em três semanas), iniciou-se novamente as aplicações, seguindo a mesma sequência descrita acima até a colheita dos tomates. No total, as caldas foram aplicadas 21 vezes, perfazendo sete aplicações para cada calda, durante o período de 150 dias. O volume de calda utilizado em cada aplicação foi de aproximadamente $500 \mathrm{~L}$ por hectare. No T3 não foi utilizado nenhum produto para controle de doenças na cultura, sendo aplicado água no mesmo volume que as caldas aplicadas nos demais tratamentos.

A variedade de tomate utilizada foi a Grandeur, que foi transplantada em mudas para as parcelas experimentais no mês de abril, em estágio inicial de desenvolvimento, com aproximadamente 30 dias após serem produzidas em bandejas com 288 células, oriundas de produtor específico de mudas para a cultura do tomateiro. Cada parcela tinha cinco linhas de plantio, com espaçamento entre linhas de $1 \mathrm{~m}$ e de $0,60 \mathrm{~m}$ entre plantas, totalizando 16.666 plantas por hectare. A adubação do tomateiro seguiu as recomendações do Manual de Adubação e Calagem para os Estados do RS e de SC (CQFS - RS/SC, 2016), através da adição de adubo mineral (fórmula 10-20-10 de Nitrogênio, Fósforo e Potássio) no momento 
do plantio. O controle de pragas foi realizado através da aplicação do inseticida a base de óleo de Nim (Azadirachta indica) em todos os tratamentos testados.

As avaliações realizadas nesse estudo, foram as produtividades nos diferentes tratamentos, o número de frutos por planta e o peso médio de tomates. A produtividade da cultura foi determinada por ocasião da colheita, colhendo-se os frutos nas três linhas centrais de cada parcela e, após, realizando-se a pesagem para posterior transformação em quilogramas por planta e por hectare. Em relação ao número de frutos por planta, no momento da colheita foram contabilizados todos os frutos em cada planta das linhas úteis de cada parcela, para posterior cálculo das médias de número de frutos por planta. Após a colheita, com a soma dos pesos dos frutos, foi calculado o peso médio de frutos por planta em cada tratamento testado nesse estudo.

Os dados obtidos foram submetidos à análise de variância utilizando os procedimentos disponíveis no pacote estatístico Sisvar (FERREIRA, 2011), através do teste de Tukey a 5\% de probabilidade.

\section{RESULTADOS E DISCUSSÃO}

A produtividade média por planta, para os tratamentos T1 (convencional), T2 (em transição para orgânico) e T3 (testemunha) foi de 3,6; 3,2 e 2,5 kg planta ${ }^{-1}$, respectivamente (Figura 1).

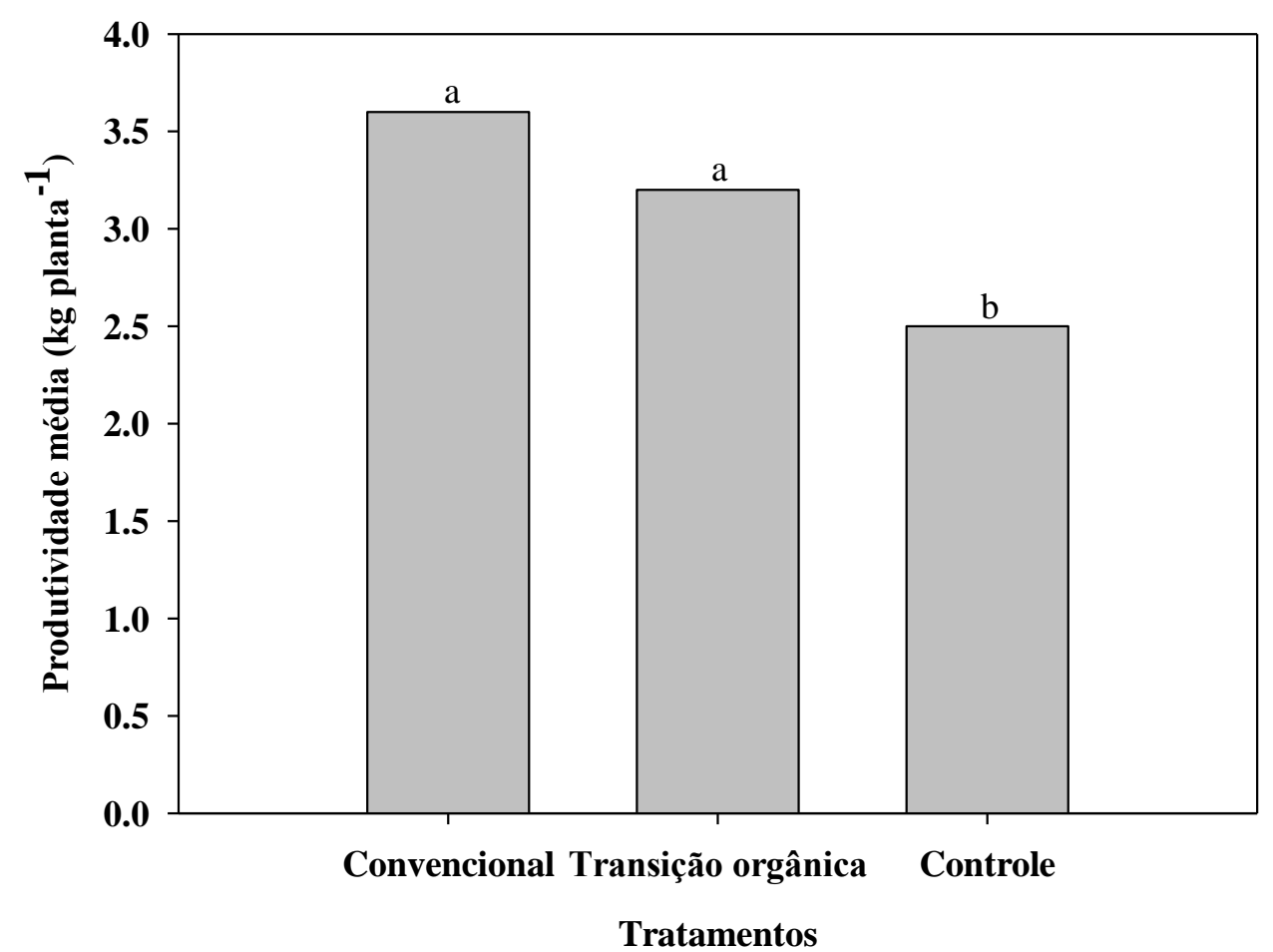

Figura 1. Produtividade média por planta dos tomateiros conduzidos em estufa nos três tratamentos avaliados. Letras diferentes nas barras indicam diferença significativa pelo teste de Tukey $(\mathrm{p}<0,05)$. Average yield per plant of greenhouse tomatoes grown under three treatments. Different letters in the bars indicate significant difference by the Tukey test $(p<0.05)$. 
Para a produtividade média por planta foi observado diferença significativa para os tratamentos T1 e T2 em relação ao T3, o qual apresentou produção inferior de 31 e $22 \%$ a menos que os tratamentos T1 e T2, respectivamente. Segundo a Gondim (2016), no cultivo convencional de tomates em estufas, pode-se alcançar produtividade de até $10 \mathrm{~kg}$ planta $^{-1}$. Entretanto, o cultivo de tomateiros em estufas pode apresentar relativas variações na mesma, em virtude de interações das cultivares com o ambiente e as práticas culturais empregadas (CALIMAN et al., 2005; GUALBERTO et al., 2007). Em estudo realizado por Luz et al. (2007), os autores compararam a produção de tomates conduzidos nos sistemas convencional e orgânico em estufa e obtiveram produtividades no sistema convencional de $4 \mathrm{~kg}_{\text {planta }}{ }^{-1}$ no período de verão e $5 \mathrm{~kg}_{\text {planta }}{ }^{-1}$ no inverno. Já no sistema orgânico a produção foi de $4 \mathrm{~kg}$ planta $^{-1}$ no período de verão e inverno. Esses resultados foram superiores aos obtidos no presente estudo, porém, ambos os estudos demonstram que a produção no sistema convencional é superior ao orgânico.

Para a variável produtividade média por hectare o estudo registrou para os tratamentos $\mathrm{T} 1, \mathrm{~T} 2$ e T3 valores de 60, 53,3 e 41,6 $\mathrm{Mg} \mathrm{ha}^{-1}$, respectivamente, com diferença significativa entre os tratamentos T1 e T2 em relação ao T3 (Figura 2).

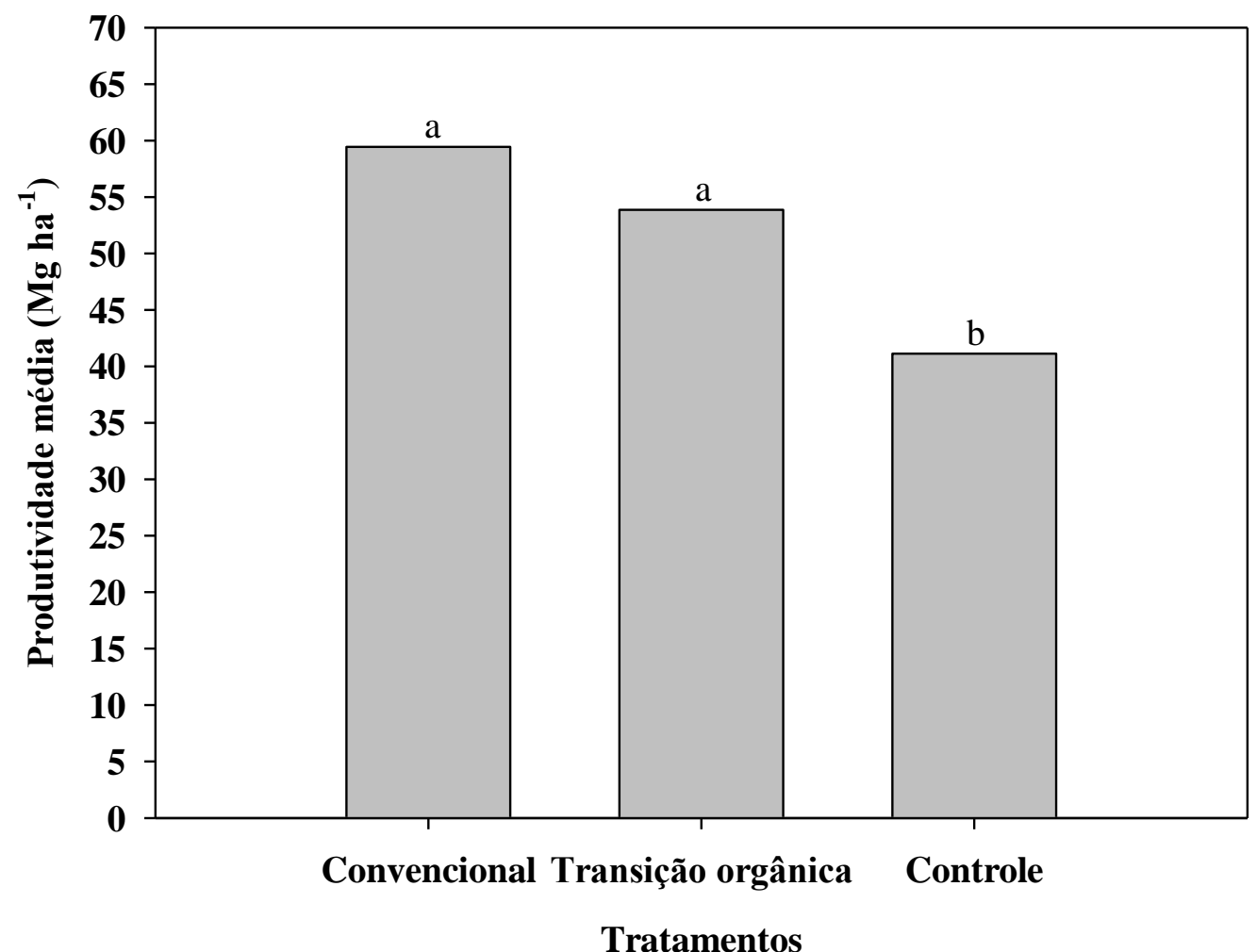

Figura 2. Produtividade média por hectare de tomate cultivado em estufa nos três tratamentos avaliados. Letras diferentes nas barras indicam diferença significativa pelo teste de Tukey $(\mathrm{p}<0,05)$. Average yield per hectare of greenhouse tomatoes grown under three treatments. Different letters in the bars indicate significant difference by the Tukey test $(p<0.05)$.

Os resultados obtidos neste estudo estão próximos aos da média brasileira de produtividade de tomate, que atualmente é de $64 \mathrm{Mg} \mathrm{ha}^{-1}$ (IBGE, 2019). Isso demostra a possibilidade de atingir produtividades satisfatórias com diferentes sistemas de produção de tomates, permitindo reduzir a entrada de insumos externos na propriedade, diminuindo custos 
de produção e garantindo a soberania alimentar e de produção aos agricultores familiares com baixo nível tecnológico de cultivo.

Em relação ao número de tomates por planta, os valores encontrados foram de 20, 22 e 21, nos tratamentos T1, T2 e T3, respectivamente, não apresentando diferença significativa entre os mesmos. Esses resultados diferem dos encontrados por Machado-Neto (2014), que ao compararem a produtividade de duas cultivares de tomates (Siluet e Santa Clara) conduzidas em sistema de cultivo orgânico e de cultivo tradicional, encontraram superioridade no sistema de cultivo orgânico, com 40 e 20 frutos, respectivamente, quando comparados ao sistema convencional que produziu 33 e 18 frutos, respectivamente.

Para a variável peso médio de tomates, a massa média dos frutos para os tratamentos T1, T2 e T3 foi de 180, 145 e 120 g, respectivamente, apresentando diferença significativa entre todos os tratamentos (Figura 3).

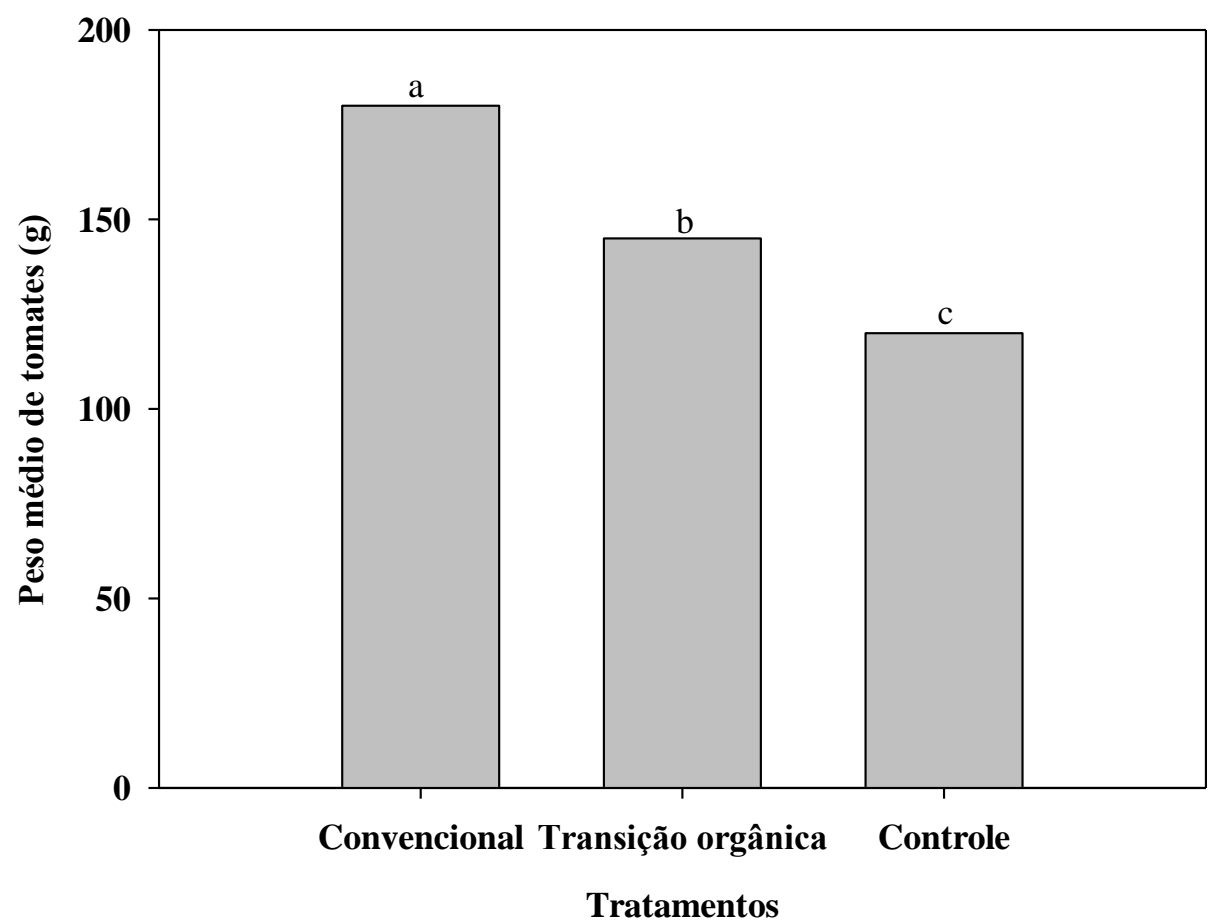

Figura 3. Peso médio de tomates nos três tratamentos avaliados. Letras diferentes nas barras indicam diferença significativa pelo teste de Tukey $(\mathrm{p}<0,05)$. Average weight of greenhouse tomatoes grown under three treatments. Different letters in the bars indicate significant difference by the Tukey test ( $p<0.05)$.

Os tomates obtidos no T1 apresentaram peso médio superior aos obtidos no T2 e T3 (Figura 3). Segundo Ferreira et al. (2005), os tomates produzidos de forma orgânica apresentam predominância de frutos menores. No entanto, os resultados obtidos no presente estudo para os três tratamentos são superiores aos encontrados por Teodoro et al. (2015), que avaliando em estufa a influência de cinco compostos orgânicos na adubação de plantio e de cobertura de tomate híbrido do tipo Caqui, obtiveram peso médio de 88,8 g de tomate. Após oito anos de cultivo de tomates de forma orgânica em estudo desenvolvido no estado do Espírito Santo, Souza (2005) observou frutos considerados pequenos, corroborando com os 
resultados obtidos no presente estudo, pois está de certa forma em uma transição para a produção orgânica de tomates, a qual apresentou mais frutos, mas de menor tamanho, além de formatos e cores não muito aceitos pelo mercado convencional.

Uma vista geral dos frutos de tomates dos três tratamentos avaliados neste trabalho pode ser observada na Figura 4, após serem colhidos.

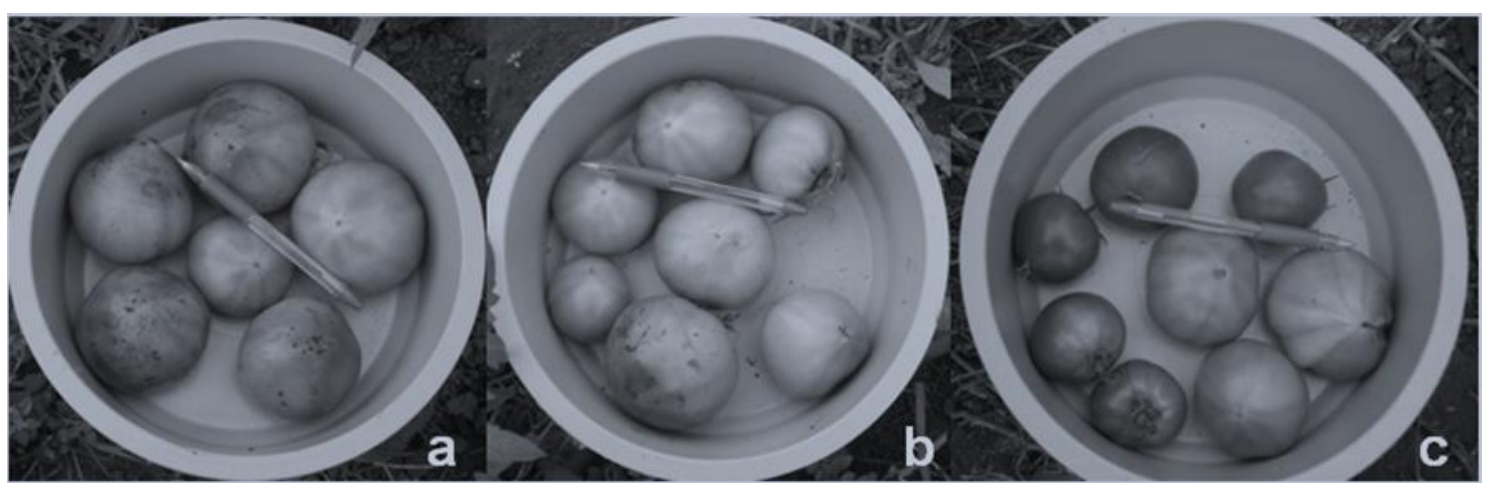

Figura 4. Frutos de tomate nos três tratamentos avaliados. a) T1- convencional; b) T2 transição para orgânico e; c) T3 - testemunha. Fruits of greenhouse tomatoes grown under three treatments. a) T1 - Conventional cropping system; b) T2 - transition to organic cropping system and; c) T3 - control.

Com os resultados obtidos neste trabalho, foi possível verificar que a produtividade dos tomateiros no sistema de transição orgânica, em termos gerais, é menor quando comparada ao tratamento convencional, porém, apresentou maior número de frutos, embora de menor tamanho. Apesar disso, esses resultados não afetariam a lucratividade, pois segundo Luz et al. (2007) o custo da produção orgânica é $17,1 \%$ mais baixo e a lucratividade $113,6 \%$ maior quando comparado ao tratamento convencional. Mesmo sendo este experimento uma transição para o cultivo orgânico, estas informações sobre a viabilidade econômica devem ser levadas em consideração.

Conforme Braga (2014), os consumidores de orgânicos na cidade de São Paulo estão dispostos a pagar mais pelos produtos, pois estes não apresentam resíduos de agrotóxicos, os quais podem fazer mal a saúde do consumidor. Segundo o mesmo autor, os consumidores de orgânicos estão na faixa etária entre 31 e 50 anos e que recebem rendas que variam entre 9 a 19 salários mínimos, o que permite a aquisição de orgânicos, mesmo em situações em que estes tenham maior preço de comercialização, pois a questão da saúde é, sem dúvidas, o motivo que aparece em primeiro lugar nas pesquisas. Ainda, de acordo com Ferreira; Bragança Coelho (2017) a busca por alimentos mais saudáveis, como os orgânicos, apresenta fortalecimento em nível mundial e nacional, pois são considerados livres ou com menor concentração de agrotóxicos, produtos estes, que em excesso podem causar diversas doenças, entre elas, o câncer.

Os dados evidenciaram que o T1 é o mais produtivo, com 0,4 $\mathrm{kg} \mathrm{planta}^{-1}$ superior ao T2 (Figura 1), porém, possivelmente apresenta resíduos de agrotóxicos, pois conforme dados do Programa Nacional de Análise de resíduos de Agrotóxicos em Alimentos, o residual destes em tomates é elevado, estando acima dos valores permitidos em 32,6\% das amostras de tomate avaliadas em 2018 (ANVISA, 2019). 
Desta forma, fica evidente que o consumo de alimentos da agricultura convencional, a qual utiliza como técnica de manejo a aplicação contínua de agrotóxicos, aditivos e outras substâncias tóxicas, tem provocado na população a insegurança alimentar e aumentado à ocorrência de doenças associadas a estes insumos (MELO et al., 2009). Na maioria dos casos os períodos de carência dos produtos não são respeitados e, mesmo sendo respeitados, sempre haverá um percentual de resíduos nos alimentos, que com o consumo constante destes, faz com que se tornem tóxicos e deletérios à saúde humana.

Os resultados obtidos neste trabalho (Figuras 1, 2 e 3) permitiram identificar que as produtividades foram significativas quando se comparou os resultados do T2 e T3, sendo o tratamento com caldas mais efetivo do que a testemunha. Desta forma, esse experimento demonstra que o uso de caldas alternadas foi eficiente no controle fitossanitário do tomateiro. Esses resultados estão de acordo com os encontrados por Rossi et al. (2004), que avaliando a influência da homeopatia na morfologia e fisiologia de diversos vegetais, como: manjericão, alface, morango, beterraba, cenoura, tomate, milho, feijão, entre outros, observaram que esta técnica permite realizar testes combinados de vários produtos fitoterápicos, o que determinaria certos compostos no metabolismo secundário, que se alteram com a aplicação destes ingredientes, permitindo avaliar características produtivas e manejo fitossanitário. Nesse sentido, os resultados obtidos nesse estudo foram relevantes e são um indicativo que a combinação de caldas pode ser eficiente tanto no sistema de transição quanto no sistema orgânico.

\section{CONCLUSÃO}

A aplicação de caldas agroecológicas apresenta eficiência na produção de tomates em sistema de produção de transição para o orgânico, com produtividades médias por planta e hectare que não diferiram estatisticamente do tratamento convencional.

\section{REFERÊNCIAS BIBLIOGRÁFICAS}

AGÊNCIA NACIONAL DE VIGILÂNCIA SANITÁRIA - ANVISA. Programa de Análise de Resíduos de Agrotóxicos em Alimentos. Brasília, DF, 2012. Disponível em: www.anvisa.gov.br. Acesso em: 10 fev. 2019.

BRAGA, M. O comportamento de compra de produtos orgânicos: uma reflexão sobre o perfil dos consumidores através da comparação entre faixas etárias e níveis de renda familiar - uma abordagem estatística. Revista Acadêmica Eletrônica Sumaré, Santo Amaro, v. 1, n. 2, p.1$13,2014$.

BRASIL. MINISTÉRIO DA SAÚDE. AGÊNCIA NACIONAL DE VIGILÂNCIA SANITÁRIA - ANVISA. 2019. Programa Nacional de Análise de Resíduos de Agrotóxicos em Alimentos (PARA). Relatório complementar. Brasília: Anvisa. Disponível em: www.anvisa.gov.br. Acesso em: 10 fev. 2019. 
BRASIL. MINISTÉRIO DA AGRICULTURA, PECUÁRIA E ABASTECIMENTO MAPA. Instrução Normativa Conjunta SDA/SPRC no 01 de 06 de novembro de 2015. Brasília, DF, 2015. Disponível em: www.mapa.gov.br. Acesso em: 10 jan. 2019.

BRASIL. MINISTÉRIO DA AGRICULTURA, PECUÁRIA E ABASTECIMENTO MAPA. Instrução Normativa $n^{0} 46$ de 06 de outubro de 2011. Brasília, DF, 2011. Disponível em: www.mapa.gov.br. Acesso em: 09 Mar. 2019.

CAlimAN, F. R. B.; SIlVA, D. J. H.; FONTES, P. C. R.; STRINGHETA, P. C.; MOREIRA, G. R.; CARDOSO, A. A. Avaliação de Cultivares de tomateiro cultivados em ambiente protegido e em campo nas condições edafoclimáticas de Viçosa. Horticultura Brasileira, Brasília, DF, v. 23, n. 2, p.255-259, 2005.

COMISSÃO DE QUÍMICA E FERTILIDADE DO SOLO DOS ESTADOS DO RIO GRANDE DO SUL E SANTA CATARINA. Manual de calagem e adubação para os Estados do Rio Grande do Sul e Santa Catarina. 11. ed. Porto Alegre: SBCS-NRS, 2016. $376 \mathrm{p}$.

CAMPOS, A. G.; MELLO, G. J.; COVARI, L.; CARBO, L.; SILVA, J. L.; SENRA, R. E. F.; COELHO, M. F. B. A agroecologia como ciência mediadora entre a formação do agrônomo e a agricultura sustentável. Revista de Ciencia y Tecnología de América, Venezuela, v. 40, n. 3, p.172-178, 2015.

FOOD AND AGRICULTURAL ORGANIZATION - FAO. FAO Statistical Yearbook. New York, 2019. Disponível em: www.fao.com. Acesso em: 25 jun. 2019.

FERREIRA, A. S.; BRAGANÇA COELHO, A. O Papel dos Preços e do Dispêndio no Consumo de Alimentos Orgânicos e Convencionais no Brasil. Revista de Economia e Sociologia Rural, Piracicaba, v. 55, n. 4, p.625-640, 2017.

FERREIRA, D. F. A computer statistical analysis system. São Paulo: Ciência e Agrotecnologia. 2011. 1042 p.

FERREIRA, S. M. R.; QUADROS, D. A.; FREITAS, R. J. S. Classificação do tomate de mesa cultivado nos sistemas convencional e orgânico. Ciência e Tecnologia de Alimentos, Campinas, v. 25, n. 3, p.584-590, 2005.

GONDIM, A. Catálogo brasileiro de hortaliças. In: EMPRESA BRASILEIRA DE PESQUISA AGROPECUÁRIA - EMBRAPA. 2016. Disponível em: http://www.embrapa.gov.br/dados/publicacao/Catalogo\%20hortalicas.pdf. Acesso em: 08 set. 2018.

GUALBERTO, R.; OLIVEIRA, P. S. R.; GUIMARAES, A. M. Desempenho de cultivares de tomateiro para mesa em ambiente protegido. Horticultura Brasileira, Brasília, v. 25, n. 2, p.244-246, 2007.

INSTITUTO BRASILEIRO DE GEOGRAFIA E ESTATÍSTICA - IBGE. Estatística da produção pecuária. Brasília, DF, 2018. Disponível em: www.ibge.gov.br. Acesso em: 02 abr. 2019. 
LUZ, J. M. Q.; SHINZATO, A. V.; SILVA, M. A. D. Comparação dos sistemas de produção de tomate convencional e orgânico em cultivo protegido. Bioscience Journal, Uberlândia, v. 23, n. 2, p.7-15, 2007.

MACHADO NETO, A. S. Viabilidade agroeconômica da produção de tomate de 'mesa' sob diferentes sistemas de cultivo e manejo de adubação. 2014. 77 f. Tese (Doutorado em Produção Vegetal) - Universidade Estadual do Norte Fluminense Darcy Ribeiro, Campos dos Goytacazes, Rio de Janeiro, 2014.

MARINI, F. S.; XAVIER, L. H.; SILVA, D. V.; BARROS, J. R. L.; BARBOSA, G. J.; SILVA, F. J. A.; SILVA, V. Panorama da certificação de produtos orgânicos no Brasil e dos instrumentos nacionais de garantia da conformidade: uma análise a partir do Cadastro Nacional de Produtores Orgânicos. Gaia Scientia, João Pessoa, v. 10, n. 4, p.574-588, 2016.

MELO, P. C. T.; TAMISO, L. G.; AMBROSANO, E. J.; SCHAMMASS, E. S.; INOMOTO, M. M.; SASAKI, M. E. M.; ROSSI, F. Desempenho de cultivares de tomateiro em sistema orgânico sob cultivo Protegido. Horticultura Brasileira, Brasília, v. 27, n. 4, p.553-559, 2009.

NICOLA, M. P.; M. F. C. Transições em direção ao uso sustentável e conservação dos campos sulinos gaúchos: o lugar da pecuária familiar. Extensão Rural, Santa Maria, v. 23, n. 1, p.58-77, 2016.

RESENDE, G. M.; BRAGA, M. B. Produtividade de cultivares e populações de cenoura em sistema orgânico de cultivo. Horticultura Brasileira, Brasília, v. 32, n. 1, p.102-106, 2014.

ROSSI, F.; AMBROSANO, E. J.; MELO, P. C. T.; GUIRADO, N.; MENDES, P. C. D. Experiências básicas de homeopatia em vegetais. Cultura Homeopática, Piracicaba, v. 3, n. 1, p.12-13, 2004.

SAITO, M. L.; LUCCHINI, F. Substâncias obtidas de plantas e a procura por praguicidas eficientes e seguros ao meio ambiente. Jaguariúna: EMBRAPA, CNPMA, 1998. 46 p.

SANTOS, H. G. Sistema Brasileiro de Classificação de Solos. 3. ed. Brasília, DF: Embrapa, 2013. $400 \mathrm{p}$.

SOUZA, J. L. Agricultura orgânica: tecnologias para a produção de alimentos saudáveis. Vitória: INCAPER, 2005. 257 p.

SOUZA, J. L. Sistema orgânico de produção de tomate. In: INSTITUTO CAPIXABA DE PESQUISA. Assistência Técnica e Extensão Rural. Vitória: INCAPER, 2010. 67 p.

TEODORO, M. S.; SEIXAS, S. J. S.; LACERDA, M. N.; ARAÚJO, L. M. S. Efeito do uso de diferentes compostos na produção de tomate (Lycopersicum esculentum Mill) em cultivo orgânico. Revista Verde de Agroecologia, Pombal, v. 10, n. 4, p.16-20, 2015. 